Journal of Engineering and Science Research 2 (2): 66-72, 2018

e-ISSN: 2289-7127

(C) RMP Publications, 2018

DOI: $10.26666 /$ rmp.jesr.2018.2.10

\title{
Total Phenolic Contents and Antioxidant Activities of Different Herbal Tea Extracts from Turkey
}

\author{
Ferda Eser \\ Amasya University, Suluova Vocational Schools, Suluova, Amasya, Turkey
}

\begin{abstract}
The aim of the present study is to determine the total phenolic contents (TPC), DPPH radical scavenging activities, and reducing power of commercially consumed herbal teas including sage tea (ST), blackberry tea (BT), apple tea (AT), Echinacea tea (ET), lime tea (LT), rosehip tea (RT), and green tea (GT) in Turkey. For this purpose, various solvents were used for extraction of the tea samples and the results were compared in terms of total phenolic contents and antioxidant activities, as well. Hot water is found as the best solvent for the extraction of total phenolics from ST, BT, AT, and RT, respectively. On the other hand, the highest TPC values are obtained with the extraction of ET, LT, and GT in the presence of aqueous acetone $(50 \%)$ solvent system. Generally all samples gave high DPPH radical scavenging activities depending on their extraction solvents. The highest radical scavenging activity was found as $94.92 \pm 0.01 \%$ for ST in ethanol, while the lowest activity was obtained as $5.98 \pm 0.14 \%$ for BT with water extract. Ferric reducing antioxidant assay results are closed each other and the highest activity $(0.27 \pm$ $0.74 \mathrm{mM}$ Trolox) was observed in the ethanol extract of ST. Antioxidant activities and TPC of the herbal tea samples varied depending on the extraction solvent. Water or aqueous organic solvent extracts of sage tea and green tea samples gave high TPC values and antioxidant activities.
\end{abstract}

\section{Key words: Herbal tea, DPPH radical scavenging activity, Total phenolic, Reducing power}

\section{INTRODUCTION}

Tea is one of the most consumed beverages all over the world [1] and different forms of tea including fruits, fruit mixtures etc. are consumed mostly infusion of dried herbs or parts of plant species such as leaves, flowers, seeds, fruits, and roots in warm or hot water [2]. Recent studies showed that these herbal teas exhibit biological properties such as reducing the risk of chronic diseases [3] having anticarcinogenic, antiatherogenic, chemopreventive, antimicrobial, and antioxidant effects [4]. In recent years, a substantial body of evidence has indicated an important role of free radicals due to the ability to retard oxidative degradation of lipids and thereby prevent many of diseases such as cirrhosis cancer, arteriosclerosis, rheumatoid arthritis, and as well as in degenerative processes associated with aging [5-7]. It is known that phenolic constituents are responsible from the antioxidant activity of plant materials due to their redox properties in the way of absorbing and neutralizing free radicals [8].

Many investigators have studied different forms of tea samples because of their health-related properties or bioactivities such as antimicrobial and antioxidant [911]. Generally, the studies are focused on the antioxidant properties of green and black teas [12-14]. In another study, various leafly herbal tea (LHT) extracts, including rosemary, persimmon leaf, green tea, peppermint, black tea, mate tea, mulberry leaf, lotus leaf, lemongrass, rooibos, and bamboo leaf were studied in terms of their antioxidant and antimicrobial activities [15].

The interest in herbs is increasing day by day because of their strong antioxidant property which facilitates to enhance human health by the way of nutrition. Thus, in this study, 7 different herbal tea samples that believed to have many beneficial effects and mostly consumed by Turkish people are investigated for their total phenolic

Corresponding Author: Ferda Eser, Amasya University, Suluova Vocational Schools, Suluova, Amasya, Turkey, Tel:+905052128408 
contents, DPPH radical scavenging activities, and the ferric reducing antioxidant power, as well. Different solvent and solvent systems were used for the herbal tea extraction processes in order to compare the results in terms of phenolic contents and antioxidant activities. The current study can contribute to a better understanding of the health promoting and nutritional properties of mostly consumed herbal teas in Turkey.

\section{EXPERIMENT}

\section{Herbal Teas and Preparation of Extracts}

Herbal teas including sage tea (Salvia officinalis), blackberry tea (Rubus procerus), apple tea (Malus domestica), Echinacea tea (Echinacea angustifolia), lime tea (Tilia platyphyllo), rosehip tea (Rosa canina), and green tea (Camellia sinensis) were purchased from local market, Amasya, Turkey.

Extraction of the tea samples was performed using boiling water, aqueous $\mathrm{MeOH}(50 \%), \mathrm{EtOH}$, aqueous $\mathrm{EtOH}(50 \%)$, acetone, and aqueous acetone (50\%), respectively. Boiling water was used in order to obtain similar conditions during the preparation of tea for consumption. Other solvents were used for the determination of the difference in terms of phenolic contents and antioxidant activities, as well. $1 \mathrm{~g}$ of each herb was infused into $10 \mathrm{ml}$ of solvent for $5 \mathrm{~min}$ and filtered through no. 1 Whatman filter paper. The filtrates were directly used for the analyses.

\section{Folin-Ciocalteu Assay for Total Phenolics}

Each sample $(50 \mu \mathrm{l})$ was dissolved in distilled water $(950 \mu \mathrm{l})$ and sodium carbonate $(2 \%, 2.5 \mathrm{ml})$ was added to the mixture. After addition of the Folin-Ciocalteu reagent $(500 \mu \mathrm{l})$, test tubes were vortexed for 5 seconds. The samples were incubated in dark for $40 \mathrm{~min}$. At the end of the time, absorbances were recorded at $725 \mathrm{~nm}$. Gallic acid was used as standard, and total phenolic content (TPC) of the samples was expressed as gallic acid equivalent (GAE).

\section{1,1-Diphenyl-2-Picryl-Hydrazyl (DPPH) Free Radical Scavenging Activity}

The free radical scavenging activity of the herbal tea samples were carried out according to the method of Blois [16] with little modifications. The method was discussed comprehensively elsewhere [17] that DPPH radical absorbs at $517 \mathrm{~nm}$, on the other hand its absorption decreases in the presence of an antioxidant or a radical species [17]. Shortly, sample solutions $(0.2 \mathrm{ml})$ were mixed with ethanol $(3 \mathrm{ml})$. Solution of DPPH in ethanol $(1 \mathrm{mM}, 375 \mu \mathrm{l}))$ was added to the mixture. The mixture was shaken vigorously and incubated for $30 \mathrm{~min}$ in the dark at room temperature. Then the absorbance was measured at $517 \mathrm{~nm}$ using a spectrophotometer (Thermo Scientific, Ceneys 10S UV-VIS spectrophotometer). Lower absorbance of the reaction mixture indicates higher free radical scavenging activity. The percent DPPH radical scavenging effect was calculated using the following equation:

$$
\begin{aligned}
& \text { DPPH radical scavenging effect }(\%) \\
& =\left[100-\left(\mathrm{A}_{0}-\mathrm{A}_{1} / \mathrm{A}_{0}\right) \times 100\right]
\end{aligned}
$$

where $\mathrm{A}_{0}$ was the absorbance of negative control reaction and $A_{1}$ was the absorbance in the presence of the sample of herbal tea extracts or standards as positive control.

All measurements were performed in triplicate.

\section{Ferric Reducing Antioxidant Power Assay (FRAP)}

Ferric reducing antioxidant assay was carried out according to Zhu et al. [18] with slight modification. Phosphate buffer ( $\mathrm{pH} 7.5,0.2 \mathrm{M}, 0.2 \mathrm{ml}$ ) solution was added to the each of herbal tea extracts $(0.2 \mathrm{ml})$. After the addition of potassium ferric cyanide $(1 \%, 0.2 \mathrm{ml})$, the mixture was incubated at $50^{\circ} \mathrm{C}$ for $20 \mathrm{~min}$. Thereafter, trichloroacetic acid $(10 \%, 0.2 \mathrm{ml})$ was added to the mixture and vortexed for $5 \mathrm{sec}$. Distilled water $(0.8 \mathrm{ml})$ and $\mathrm{FeCl}_{3}(0.1 \%, 0.2 \mathrm{ml})$ were added and the absorbances were measured $655 \mathrm{~nm}$. The reducing capacity of the herbal tea samples was calculated with reference to the reaction signal given by a Trolox ${ }^{\mathrm{TM}}$ solution. FRAP values were expressed as $\mathrm{mM}$ Trolox ${ }^{\mathrm{TM}}$.

\section{RESULTS AND DISCUSSION}

Some compounds give an electron or hydrogen atom to DPPH radical that results decolorization of purple colored solution of DPPH in methanol. The importance of radical scavenging activity is due to the harmful effects of free radicals to human body which present in biological systems and foods, as well. Formation of large amount of free radicals cause fast oxidation of lipids in nourishments thus decrease their quality. The method is preferred because of the fact that it can apply in a short time and large number of samples can be analyzed in a short period of time. Additionally, it is possible to detect natural products at low concentrations [19]. In addition, the method has been used extensively in the prediction of antioxidant 
activities due to its relatively short time required analysis.

Many studies were conducted on antioxidant activity of herbal teas $[15,20-21]$ and our findings are parallel to the previous reports $[22,-23]$. Previous studies revealed that there is a linear relationship between total phenolic content and antioxidant activity [24-26]. Due to the presence of hydroxyl groups, phenols have the ability to destroy radicals. Formation of stable phenoxyl radical occurs after giving of hydrogen atoms of phenols to radicals. Therefore, determination of the phenolic contents of plant samples is important in the prediction of the antioxidant activity [27-29]. Usually, DPPH radical scavenging activity depends on the structures of flavonoids and their arrangements of hydroxyl groups. It is reported that, hydroxyl groups at B ring which are substituted at 3,4- position (i.e., ortho 3, 4,-), hydroxyl groups at meta 5,7 position at ring A, have high radical scavenging activity It has been further reported that no single compound was able to react with all kinds of radicals [30-31].

FRAP is a simple, fast, and cheap method that used for the determination of hydrophilic and lipophilic antioxidants [32]. For the prediction of the antioxidant activity of a sample, reducing power may serve as an indicator. This reducing power was observed according to the ferric ions $\left(\mathrm{Fe}^{3+}\right)$ - the ferrous ions $\left(\mathrm{Fe}^{2+}\right)$ transformation [33].

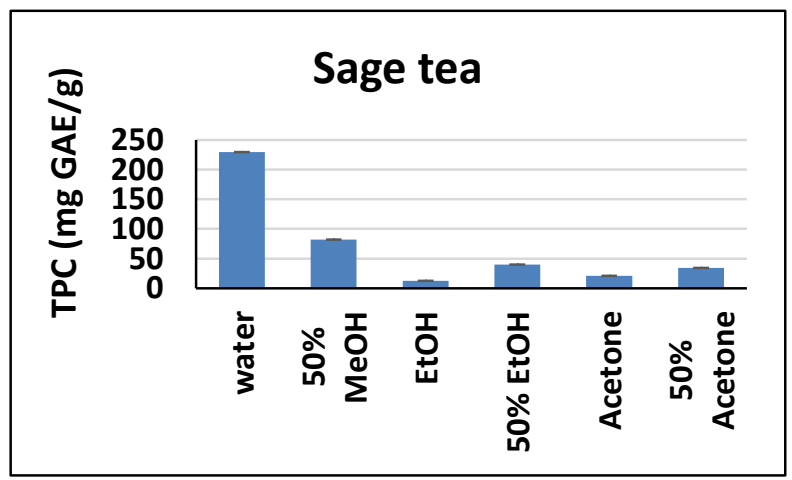

Figure 1 Total phenolic contents of different solvent extracts of sage tea

Figure 1 indicates the total phenolic contents of the different solvent extracts of sage tea. As seen from figure 1, it is clear that hot water extract of sage tea has the highest phenolic content. The high total phenolic content (TPC) in sage tea water extract $(229.21 \mathrm{mg}$ $\mathrm{GAE} / \mathrm{g}$ ) indicates that the sample contains more watersoluble phenolic compounds. Especially, phenolic acids are more water-soluble than other organic solvents [34]. The lowest TPC is obtained in the presence of EtOH solvent. The phenolic contents of other extracts of sage tea samples decrease in the order of water $(\mathrm{A})>\mathrm{MeOH}$ $50 \%$ (B) $>$ EtOH 50\% (D) > Acetone 50\% (F) > Acetone (E) $>\mathrm{EtOH}(\mathrm{C})$.

Figure 2 Total phenolic contents of different solvent extracts of blackberry tea

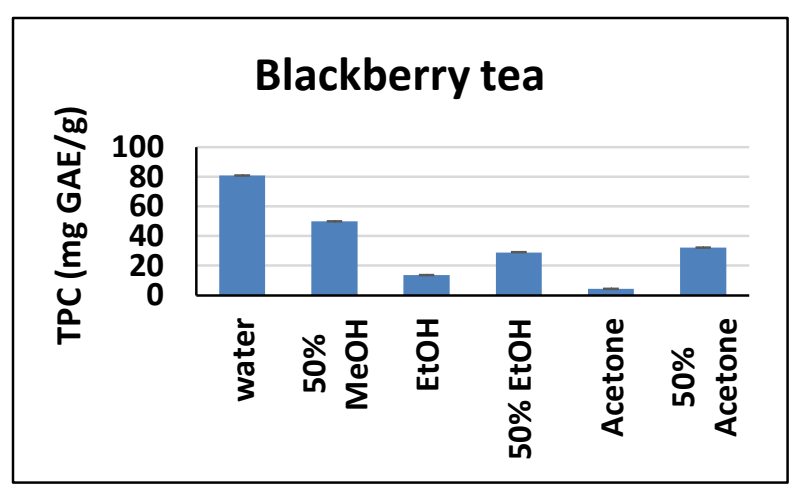

Figure 3 Total phenolic contents of different solvent extracts of apple tea

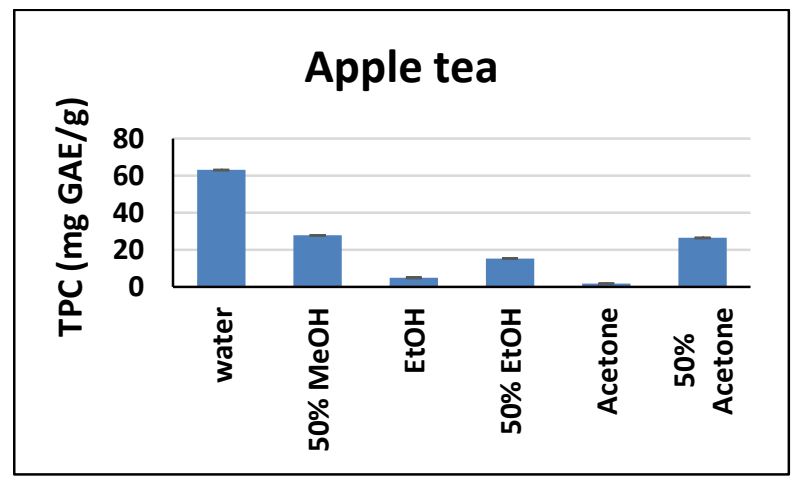

Similar results of TPC in terms of solvent effect for sage tea are obtained for blackberry and apple tea samples, respectively. The highest TPC is obtained with water extracts of blackberry tea (BT) and apple tea (AT) with the values of $80.77 \mathrm{mg} \mathrm{GAE} / \mathrm{g}$ and $63.06 \mathrm{mg}$ GAE/g, respectively. Acetone extracts of both BT and AT samples have lowest TPC. Generally, aqueous solvents gave higher total phenolic values than their absolute organic solvents (Figure 2, Figure 3). 


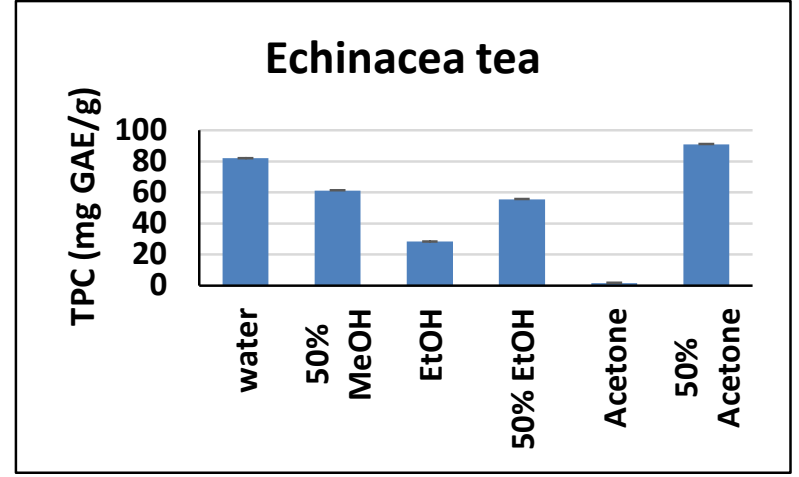

Figure 4 Total phenolic contents of different solvent extracts of Echinacea tea

Highest TPC value $(90.96 \mathrm{mg} \mathrm{GAE} / \mathrm{g})$ was obtained with acetone (50\%) for Echinacea tea (Figure 4). It is clear that, water-soluble phenolic compounds are higher than absolute organic solvents. TPC of ET decreased as such: $\mathrm{F}>\mathrm{A}>\mathrm{B}>\mathrm{D}>\mathrm{C}>\mathrm{E}$ (Figure 4).

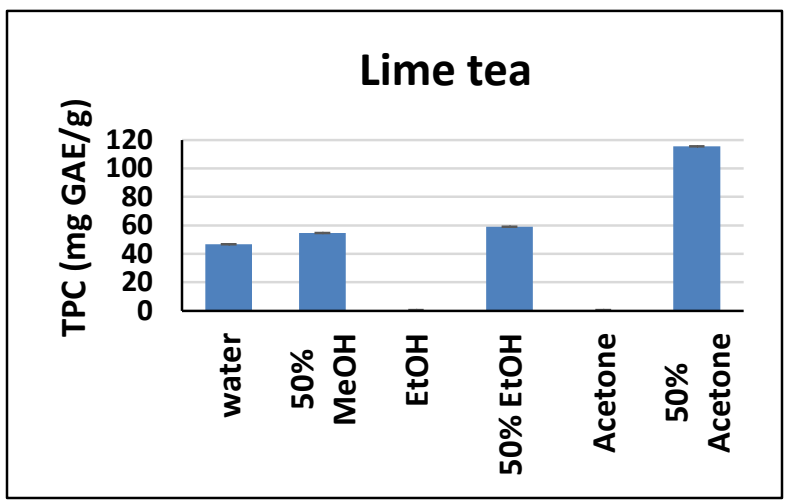

Figure 5 Total phenolic contents of different solvent extracts of lime tea

Figure 5 depict that acetone (50\%) extract of LT contain higher amount of phenolics $(115.44 \mathrm{mg}$ $\mathrm{GAE} / \mathrm{g}$ ) as compared to others. It is reported that, acetone-water solvent system is effective for the extraction of tannins [35]. Furthermore, the solubility of phenolic compounds is higher in alcohols and acetone due to their intermediate polarity nature rather than more polar (e.g. water) solvents [36]. Previous studies revealed that, acetone-water solvent system is able to extract high levels of phenolic compounds from other plants [37-38].

The use of acetone-water mixture as solvent for food products is generally regarded as safe [39-40].

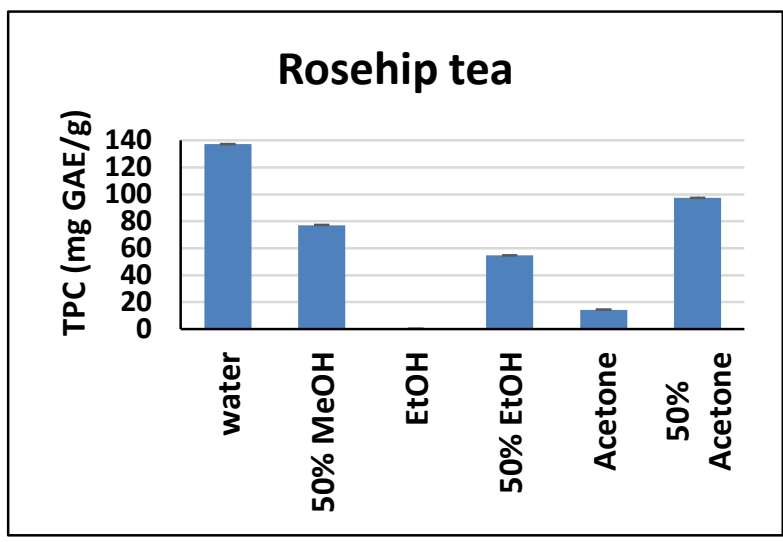

Figure 6 Total phenolic contents of different solvent extracts of rosehip tea

Water extract of rosehip tea has the highest phenolic content (137.36 mg GAE/g) followed by acetone 50\% (97.36 mg GAE/g) and $\mathrm{MeOH} 50 \%$ (77.14 mg GAE/g), respectively (Figure 6). The results from our study were similar to the previous reports for total phenolic content in Rosa canina L. from Bulgaria [41].

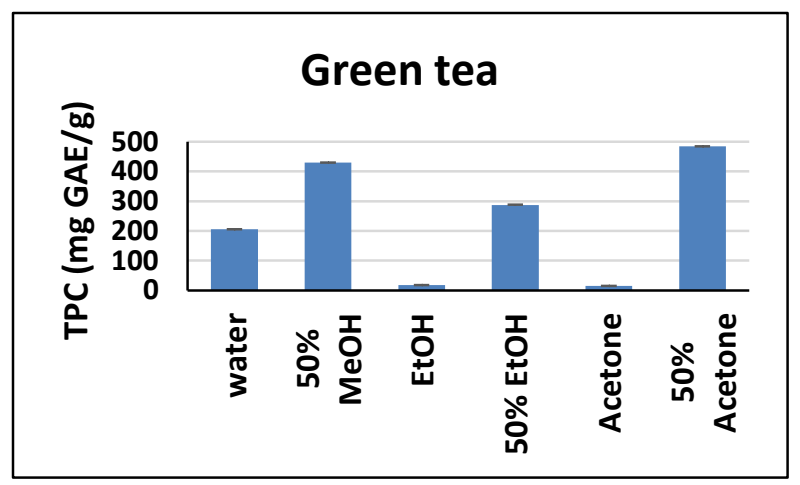

Figure 7 Total phenolic contents of different solvent extracts of green tea

Aqueous organic solvents are better than either water or absolute organic solvents for the extraction of phenolic compounds from green tea. Highest TPC (484.40 mg GAE/g) is obtained with acetone (50\%), followed by $\mathrm{MeOH} 50 \%$ (429.99 mg GAE/g), and EtOH $50 \%$ (287.51 mg GAE/g), respectively (Figure 7). The findings are parallel with the study of Do et al. [42].

Comparison of TPC of water extracts for different herbal tea samples is given in figure 8. ST has the highest phenolic content value (229.21 mg GAE/g) while LT has the lowest value (46.62 mg GAE/g). TPC values of the samples decreases in the order of: ST (229.21 mg GAE/g) > GT (205.99 mg GAE/g) > RT (137.36 mg GAE/g) > ET (81.96 mg GAE/g) > BT 
(80.77 mg GAE/g) > AT (63.07 mg GAE/g) > LT (46.62 mg GAE/g), respectively.

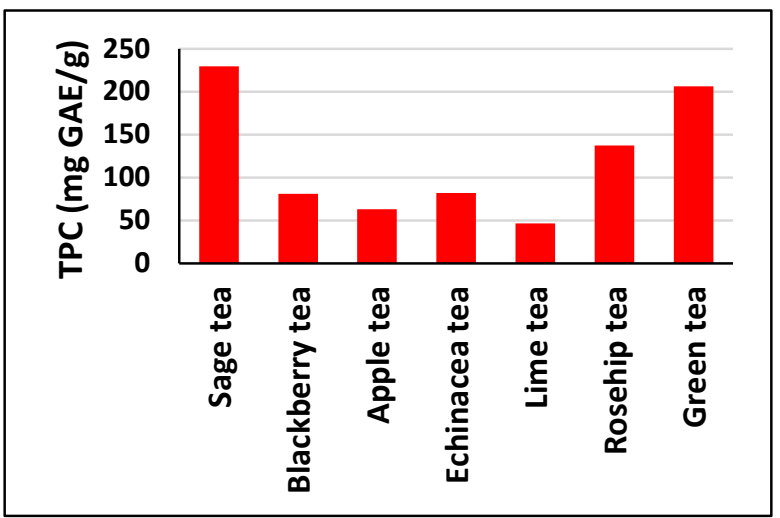

Figure 8 Total phenolic contents of water extracts of herbal tea samples

Different classes of phenols can be extracted from plants with various solvents and solvent mixtures depending on their polarities [43]. Due to the fact that each plant contains different types and amount of phenolic compounds. Therefore, determination of the ideal solvent is an important step for the extraction of the targeted compounds [44-45].

DPPH and FRAP assay results are given in Table 1. Inhibition of DPPH radicals by ST extracts is ranged from $71.51 \%$ in the acetone extract to $94.92 \%$ in ethanol extract. Although ethanol extract of ST has low TPC value (12.29 mg GAE/g), the highest DPPH and FRAP activity results are obtained with EtOH extract. This can be explained by the chemical structures of the phenolics which can be extracted with organic solvents. In another words, phenolics of ST which have lower polarities are more effective in the scavenging of DPPH radicals and reducing ferric ions, as well. High inhibition values are obtained for GT, as well. DPPH radical scavenging activity ranged from $70.99 \%$ to $89.49 \%$ in the presence of acetone and ethanol solvents for GT, respectively. Effect of solvent type on DPPH scavenging activity is more significant for other herbal tea samples under studied. For instance, DPPH activity ranged from $5.98 \%$ in the water extract to $91.67 \%$ in EtOH (50\%) extract. A solvent may be efficient on one plant and less efficient on another. The phenomena may be explained by the fact that the recovery of antioxidant compounds such as polyphenols from plant materials is influenced by the solubility of the phenolic compounds in the solvent used for the extraction. Although FRAP assay results are closed each other, the highest value $\left(0.27 \pm 0.74 \mathrm{mM}\right.$ Trolox $\left.^{\mathrm{TM}}\right)$ is obtained for ST with EtOH (Table 1).

Table 1 DPPH and FRAP assay results of herbal tea samples; ST: Sage tea, BT: Blackberry tea, AT: Apple tea, ET: Echinacea tea, LT: Lime tea, RT: Rosehip tea, GT: Green tea, A: Water, B: $\mathrm{MeOH}(50 \%), \mathrm{C}$ : EtOH, D: EtOH (50\%), E: Acetone, F: Acetone (50\%)

\begin{tabular}{|c|c|c|c|}
\hline $\begin{array}{l}\text { Herbal } \\
\text { teas }\end{array}$ & $\begin{array}{l}\text { Extract } \\
\text { solvent }\end{array}$ & DPPH (\%) & $\begin{array}{c}\text { FRAP }(\mathbf{m M} \\
\left.\text { Trolox }^{\mathrm{TM}}\right)\end{array}$ \\
\hline \multirow[t]{6}{*}{ ST } & $\mathrm{A}$ & $76.97 \pm 0.02$ & $0.13 \pm 0.03$ \\
\hline & $\mathrm{B}$ & $82.31 \pm 0.01$ & $0.18 \pm 0.11$ \\
\hline & $\mathrm{C}$ & $94.92 \pm 0.01$ & $0.27 \pm 0.74$ \\
\hline & $\mathrm{D}$ & $87.06 \pm 0.01$ & $0.18 \pm 0.04$ \\
\hline & $\mathrm{E}$ & $71.51 \pm 0.03$ & $0.17 \pm 0.04$ \\
\hline & $\mathrm{F}$ & $84.58 \pm 0.02$ & $0.17 \pm 0.33$ \\
\hline \multirow[t]{6}{*}{ BT } & $\mathrm{A}$ & $5.98 \pm 0.14$ & $0.11 \pm 0.02$ \\
\hline & $\mathrm{B}$ & $78.90 \pm 0.01$ & $0.13 \pm 0.02$ \\
\hline & $\mathrm{C}$ & $37.72 \pm 0.02$ & $0.15 \pm 0.05$ \\
\hline & $\mathrm{D}$ & $91.67 \pm 0.00$ & $0.14 \pm 0.04$ \\
\hline & $\mathrm{E}$ & $24.73 \pm 0.02$ & $0.16 \pm 0.02$ \\
\hline & $\mathrm{F}$ & $89.62 \pm 0.01$ & $0.15 \pm 0.05$ \\
\hline \multirow[t]{6}{*}{ AT } & $\mathrm{A}$ & $58.69 \pm 0.08$ & $0.12 \pm 0.09$ \\
\hline & B & $85.60 \pm 0.01$ & $0.13 \pm 0.05$ \\
\hline & $\mathrm{C}$ & $38.87 \pm 0.01$ & $0.15 \pm 0.05$ \\
\hline & $\mathrm{D}$ & $92.05 \pm 0.01$ & $0.15 \pm 0.04$ \\
\hline & $\mathrm{E}$ & $25.46 \pm 0.02$ & $0.16 \pm 0.03$ \\
\hline & $\mathrm{F}$ & $92.01 \pm 0.01$ & $0.15 \pm 0.07$ \\
\hline \multirow[t]{6}{*}{ ET } & $\mathrm{A}$ & $67.7 \pm 0.01$ & $0.11 \pm 0.07$ \\
\hline & B & $88.47 \pm 0.01$ & $0.14 \pm 0.05$ \\
\hline & $\mathrm{C}$ & $54.16 \pm 0.04$ & $0.15 \pm 0.04$ \\
\hline & $\mathrm{D}$ & $88.47 \pm 0.01$ & $0.16 \pm 0.08$ \\
\hline & $\mathrm{E}$ & $56.30 \pm 0.09$ & $0.17 \pm 0.01$ \\
\hline & $\mathrm{F}$ & $86.03 \pm 0.00$ & $0.17 \pm 0.02$ \\
\hline \multirow[t]{6}{*}{ LT } & $\bar{A}$ & $78.00 \pm 0.02$ & $0.13 \pm 0.03$ \\
\hline & B & $85.65 \pm 0.01$ & $0.14 \pm 0.04$ \\
\hline & $\mathrm{C}$ & $19.48 \pm 0.02$ & $0.15 \pm 0.03$ \\
\hline & $\mathrm{D}$ & $86.46 \pm 0.00$ & $0.15 \pm 0.04$ \\
\hline & $\mathrm{E}$ & $35.37 \pm 0.02$ & $0.16 \pm 0.03$ \\
\hline & $\mathrm{F}$ & $85.56 \pm 0.00$ & $0.15 \pm 0.09$ \\
\hline \multirow[t]{6}{*}{ RT } & $\bar{A}$ & $8.07 \pm 0.02$ & $0.11 \pm 0.03$ \\
\hline & $\mathrm{B}$ & $26.74 \pm 0.13$ & $0.13 \pm 0.01$ \\
\hline & $\mathrm{C}$ & $47.24 \pm 0.03$ & $0.15 \pm 0.01$ \\
\hline & $\mathrm{D}$ & $70.52 \pm 0.02$ & $0.14 \pm 0.04$ \\
\hline & $\mathrm{E}$ & $14.35 \pm 0.03$ & $0.16 \pm 0.09$ \\
\hline & $\mathrm{F}$ & $61.55 \pm 0.03$ & $0.14 \pm 0.05$ \\
\hline \multirow[t]{6}{*}{ GT } & $\mathrm{A}$ & $80.26 \pm 0.02$ & $0.12 \pm 0.14$ \\
\hline & $\mathrm{B}$ & $86.12 \pm 0.00$ & $0.14 \pm 0.04$ \\
\hline & $\mathrm{C}$ & $89.49 \pm 0.02$ & $0.15 \pm 0.01$ \\
\hline & $\mathrm{D}$ & $85.69 \pm 0.00$ & $0.16 \pm 0.05$ \\
\hline & $\mathrm{E}$ & $70.99 \pm 0.06$ & $0.15 \pm 0.11$ \\
\hline & $\mathrm{F}$ & $80.78 \pm 0.01$ & $0.17 \pm 0.03$ \\
\hline
\end{tabular}




\section{CONCLUSION}

The most commonly consumed 7 herbal teas were investigated for their DPPH radical scavenging properties, ferric ions reducing power, and total phenolic contents. Water and aqueous organic solvents are better for the extraction of herbal tea samples. Although considerable results were obtained for all samples depending on extraction solvent, highest values were obtained for sage and green tea samples, respectively. The herbal tea infusions analyzed in this study are generally presented high antioxidant activity in terms of free radical scavenging, thus indicating possible benefits to human health when present in the diet.

In the light of the obtained results, sage tea, Echinacea tea, lime tea and green tea can be consumed for their free radical scavenging abilities which prevented aging. Consequently, the radical scavenging activity of herbal tea differs depending on the constituent of functional compounds. Outstanding of the present study reveal that, other antioxidant activity tests and qualitative phenolic compound analysis must be done for evaluation of whole herbal tea samples.

\section{REFERENCES}

[1] Muktar, H. and Ahmad, N. 2000. Tea polyphenol: Prevention of cancer and optimizing health. The American Journal of Clinical Nutrition 71, 168-170.

[2] Aoshima, H., Hirata, S. and Ayabe, S. 2007. Antioxidant and anti-hydrogen peroxide activities of various herbal teas. Food Chemistry 103, 617-622.

[3] Craig, W.J. 1999. Health-promoting properties of common herbs. The American Journal of Clinical Nutrition 70, 491-499.

[4] Shi, W., Gong, J., Tsao, R., Kalab, M., Yang, R. and Yin, Y. 2006. Bioassay-guided purification and identification of antimicrobial components in Chinese green tea extract. Journal of Chromatography A 1125, 204-210.

[5] Kähkönen, M.P., Hopia, A.I., Vuorela, H.J., Rauha, J.P., Pihlaja, K. and Kujala, T.S. 1999. Antioxidant activity of plant extracts containing phenolic compounds. Journal of Agricultural and Food Chemistry 4, 3954-3962.

[6] Heim, K.E., Tagliaferro, A.R. and Bobilya, D.J. 2002. Flavonoid antioxidants: Chemistry, metabolism and structure-activity relationship. The Journal of Nutritional Biochemistry 13, 572-584.

[7] Lotito, S.B. and Frei, B. 2006. Consumption of flavonoid-rich foods and increased plasma antioxidant capacity in humans: Cause, consequence, or epiphenomenon? Free Radical Biology \& Medicine 41, 1727-1746.
[8] Sabela, M.I., Gumede, N.J., Singh, P., Bisetty, K. 2012. Evaluation of antioxidants in herbal tea with a laccase biosensor. International Journal of Electrochemical Science 7, 4918-4928.

[9] Frei,B. and Higdon, J.V. 2003. Antioxidant activity of tea polyphenols in vivo. The Journal of Nutrition 133, 3275-3284.

[10] Karakaya, S. and Kavas, A. 1999. Antimutagenic activities of some foods. Journal of the Science of Food and Agriculture 79, 237-242.

[11] Nihal, M., Ahmad, N. Mukhtar, H. and Wood, G.S. 2005. Antiproliferative and proapoptotic eff ects of ()-epigallocatechin-3-gallate on human melanoma: Possible implications for the chemoprevention of melanoma. International Journal of Cancer 114, 513521.

[12] Manzocco, L., Anese, M. and Nicoli, M.C. 1998. Antioxidant properties of tea extracts as affected by processing. LWT-Food Science and Technology 31, 694-698.

[13] Dufresne, C.J. and Farnworth, E.R. 2001. A review of latest research findings on the health promotion properties of tea. The Journal of Nutritional Biochemistry 12, 404-421.

[14] Chan, E.W.C., Lim, Y.Y., Chong, K.L., Tan, J.B.L. and Wong, S.K. 2010. Antioxidant properties of tropical and temperate herbal teas. Journal of Food Composition and Analysis 23, 185-189.

[15] Oh, J., Jo, H., Cho, A.R., Kim, S.J. and Han, J. 2013. Antioxidant and antimicrobial activities of various leafly herbal teas. Food Control 31, 403-409.

[16] Blois, M.S. 1958. Antioxidant Determinations by the Use of a Stable Free Radical. Nature 26, 1199-1200.

[17] Elmastas, M., Demirtas, I., Isildak, O. and AboulEnein, H.Y. 2006. Antioxidant activity of S-carvone isolated from spearmint (Mentha spicata L. fam Lamiaceae). Journal of Liquid Chromatography and Related Technologies 29, 1564-1575.

[18] Zhu, Q.Y., Hackman. R.M., Ensunsa, J.L., Holt, R.R. and Keen, C.L. 2002. Antioxidative activities of oolong tea. Journal of Agricultural and Food Chemistry 2, 6929-6934.

[19] Gulcin, İ., Elias, R., Gepdiremen, A., Taoubi, K. and Koksal, E. 2009. Antioxidant secoiridoids from fringe tree (Chionanthus virginicus L.). Wood Science and Technology 43, 195-212.

[20] Alarkon, E., Campos, A.M., Edwards, A.M., Lissi, E. and Lopez-Alarkon, C. 2008. Antioxidant capacity of herbal infusions and tea extracts: A comparison of ORAC-fluorescein and ORAC-pyrgallol red methodologies. Food Chemistry 107, 1114-1119.

[21] Almajano, M.P., Carbo, R., Jiménez, J.A.L. and Gordon, M.H. 2008. Antioxidant and antimicrobial activities of tea infusions. Food Chemistry 108, 55-63.

[22] Özdatlı, Ş., Sipahi, H., Charehsaz, M. Aydın, A. and Yeşilada, E. 2014. Bitki çaylarına bal ilavesinin total antioksidan kapasitesine etkisi. Marmara Pharmaceutical Journal 18, 147-152.

[23] Moraes-de-Souza, R.A., Oldoni, T.L.C., Regitanod'Arce, M.A.B. and Alencar, S.M. 2008. Antioxidant 
activity and phenolic composition of herbal infusions consumed in Brazil. CyTA-Journal of Food 6, 41-47.

[24] Djeridane, A., Yousfi, M., Nadjemi, B., Boutassouna, D., Stocker, P. and Vidal, N. 2006. Antioxidant activity of some Algerian medicinal plants extracts containing phenolic compounds. Food Chemistry 97, 654-660.

[25] Kim, D.O., Chun, O.K., Kim, Y.J., Moon, H.Y. and Lee, C.Y. 2003. Quantification of polyphenolics and their antioxidant capacity in fresh plums. Journal of Agricultural and Food Chemistry 51, 6509-6515.

[26] Kim, D.O., Jeong, S.W. and Lee, C.Y. 2003. Antioxidant capacity of phenolic phytochemicals from various cultivars of plums. Food Chemistry 81, 321326.

[27] Das, N.P. and Pereira, T.A. 1990. Effects of flavonoids on thermal autooxidation of palm oil: structure-activity relationship. Journal of the American Chemists' Society 67, 255-258.

[28] De Gaulejac, N.S.C., Glories, Y. and Vivas, N. 1999. Free radical scavenging effect of anthocyanins in red wines. Food Research International 32, 327-333.

[29] Hatano, T., Edamatsu, R., Hiramatsu, M., Mori, A. and Fujita, Y. 1989. Effects of the interaction of tannins with co-existing substances. VI: effects of tannins and related polyphenols on superoxide anion radical and on 1,1-diphenyl-2-picrylhydrazyl radical. Chemical and Pharmaceutical Bulletin 37, 2016-2021.

[30] Kondo, K., Kurihara, M., Fukuhara, K., Tanaka, T., Suzuki, T., Miyata, N. and Toyoda, M. 2000. Conversion of procyanidin B-type (catechin dimer) to A-type: evidence for abstraction of C-2 hydrogen in catechin during radical oxidation. Tetrahedron Letters 41, 485-488.

[31] Rice-Evans, C.A., Miller, N.J. and Paganga, G. 1996. Structure-antioxidant activity relationships of flavonoids and phenolic acids. Free Radical Biology \& Medicine 20, 933-956.

[32] Prior, R.L., Wu, X. and Schaich, K. 2005. Standardized methods for the determination of antioxidant capacity and phenolics in foods and dietary supplements. Journal of Agricultural and Food Chemistry 53, 4290-4302.

[33] Demirtas, I., Ayhan, B., Sahin, A., Aksit, H., Elmastas, M. and Telci, I. 2010. Antioxidant activity and chemical composition of Sideritis libanotica Labill. ssp. linearis (Bentham) Borm. (Lamiaceae). Natural Product Research 25, 1512-1523.

[34] Galanakis, C.M., Tornberg, E. amd Gekas, V. 2010. Clarification of high-added value products from olive mill wastewater. Journal of Food Engineering, 99, 190-197.
[35] Tatiya, A.U., Tapadiya, G.G., Kotecha, S. and Surana, S.J. 2011. Effect of solvents on total phenolics, antioxidant and antimicrobial properties of Bridelia retusa Spreng. stem bark.

[36] Bhebhe, M., Füller, T.N., Chipurura, B. and Muchuweti, M. 2016. Effect of solvent type on total phenolic content and free radical scavenging activity of black tea and herbal infusions. Food Analytical Methods 9, 1060-1067.

[37] Tabart, J., Kevers, C., Sipel, A., Pincemail, J., Defraigne, J.O. and Dommes, J. 2007. Optimisation of extraction of phenolics and antioxidants from black currant leaves and buds and of stability during storage. Food Chemistry, 105, 1268-1275.

[38] Vatai, T., Škerget, M. and Knez, Ž. 2009. Extraction of phenolic compounds from elder berry and different grape marc varieties using organic solvents and/or supercritical carbon dioxide. Journal of Food Engineering 90, 246-254.

[39] Bonilla, F., Mayen, M., Merida, J. and Medina, M. 1999. Extraction of phenolic compounds from red grape marc for use as food lipid antioxidants. Food Chemistry 66, 209-215.

[40] Meneses, N.G., Martins, S., Teixeira, J.A. and Mussatto, S.I. 2013. Efficacy of different solvents for extraction of antioxidant phenolic compounds from brewer's spent grains. In XV Congreso Nacional de Biotecnología y Bioingeniería.

[41] Angelov, G., Boyadzhieva, S.S. and Georgieva, S.S. 2014. Rosehip extraction: Process optimization and antioxidant capacity of extracts. Central European Journal of Chemistry 12, 502-508.

[42] Do, Q.D., Angkawijaya, A.E., Tran-Nguyen, P.L., Huynh, L.H., Soetaredjo, F.E., Ismadji, S. and Ju, Y.H. 2014. Effect of extraction solvent on total phenol content, total flavonoid content, and antioxidant activity of Limnophila aromatica. Journal of Food and Drug Analysis 22, 296-302.

[43] Koffi, E., Sea, T., Dodehe, Y. and Soro, S. 2010.. Effect of solvent type on extraction of polyphenols from twenty three Ivorian plants. Journal of Animal and Plant Sciences (JAPS) 5, 550-558.

[44] Chan, S.W., Lee, C.Y., Yap, C.F., Aida, W.W. and Ho, C.W. 2009. Optimisation of extraction conditions for phenolic compounds from limau purut (Citrus hystrix) peels. International Food Research Journal 16, 203-213.

[45] Sultana, B., Anwar, F. and Ashraf, M. 2009. Effect of extraction solvent/technique on the antioxidant activity of selected medicinal plant extracts. Molecules, 14, 2167-2180. 